\title{
The Low Price Anomaly: the Intriguing Case of the Polish Stock Market
}

\author{
Adam Zaremba ${ }^{1}$, Szymon Okon ${ }^{1}$, Andrzej Nowak ${ }^{1}$, Przemysław Konieczka ${ }^{2}$ \\ ${ }^{1}$ Poznan University of Economics and Business \\ Niepodleglosci al., 10, 61-875 Poznan, Poland \\ E-mail.adam.zaremba@ue.poznan.pl,szymon.okon@ue.poznan.pl,andrzej.pawel.nowak@googlemail.com \\ ${ }^{2}$ Warsaw School of Economics \\ Niepodleglosci al., 162, 02-554 Warsaw, Poland \\ E-mail.przemystaw.konieczka@doktorant.sgh.waw.pl \\ cross $^{r e f}$ http://dx.doi.org/10.5755/j01.ee.27.2.13490
}

This study investigates the low-price effect on the Polish stock market. By adopting sorting, cross-sectional tests and checks of the monotonic relation, we have examined the performance of the portfolios formed on the prices of over 850 companies listed on the Polish stock market within the years 2000-2014. Contrary to the globally prevailing evidence, the expensive stocks have significantly outperformed the cheap stocks. Additional sorts on value, size and momentum may be used further to improve the price-based strategies while the strongest anomaly has been identified among the growth companies. We hypothesize that the reverse character of the low-price anomaly may be explained by the impact of another phenomena: the underperformance of lottery-stocks. With the exception of the growth stocks, the reverse low-price effect is no longer significant after the exclusion of NewConnect companies. Finally, by adopting an alternative methodology, we have provided convincing out-of-sample evidence in support of the hypothesis of Baker et al. (2009) stating that corporate managers cater to investors by splitting their company shares in response to time-varying catering incentives.

Keywords: Low-Price Effect, Polish Stock Market, Warsaw Stock Exchange, Cross-Section Of Stock Returns, Splits, Catering Theory, Share Prices, Stock Market Anomalies, Behavioral Finance, Factor Investing, NewConnect, Lottery Stocks.

\section{Introduction}

Studies of cross-sectional asset pricing anomalies have proliferated in academic literature in past decades. While Harvey et al. (2015) reviewed 315 asset-pricing factors from tier-one journals, Jacobs (2015) studied 100 cross-sectional effects from academic publications. These publications sparked a lot of interest among investors. Nevertheless, one particular cross-sectional anomaly has somehow largely escaped the attention of the academic community: the lowprice effect. It is a stock anomaly that low priced shares significantly outperform high priced shares on a riskadjusted return basis (Fritzmeier, 1936; Hwang \& Lu, 2008).

The aim of this paper is to investigate the low-price anomaly on the Polish market and its potential interactions with size, value and momentum effects. Furthermore, using a methodology alternative to Baker et al. (2009), we examine the catering hypothesis put forward by these authors, while using Polish share prices.

Our study is based on examination of over 850 companies listed on the Polish stock market in the years 2000-2014. The choice of the Warsaw Stock Exchange as the object of our research is no coincidence. In this paper, we hypothesize that the low-price effect may be related to another concept in financial markets: lottery stocks (Kumar, 2009).

What are lottery stocks? These are stocks with characteristics that make them resemble lotteries to some extent, i.e., they have very small probability of a large return. Investors are willing to accept negative expected value to buy a possibility of a big payoff. The lottery stocks share usually a number of common traits, i.e., low prices, high variances and positively skewed returns. Importantly, lottery stocks usually markedly and significantly underperform the market (Kumar, 2009; Eraker \& Ready, 2013).

Interestingly, the low-price premium to some extent contradicts the effect of lottery-like stocks. While the first concept suggests positive abnormal returns from a group of low-priced stocks, the other supplies theoretical and empirical evidence that such stocks may in fact underperform. As a result, we hypothesize that the low-price effect may be largely country-specific. On some markets, the low-price effect may prevail while on other ones, it may become dominated by the lottery-stocks phenomenon. Given the scarce geographical scope of previous studies on lowprice effect, the research was apparently confined to the first type of markets.

So why did we choose Poland? The Polish stock market appears relatively unique in terms of the lottery-stocks anomaly, at both the stock and investor level. There are four basic reasons supporting our belief that investigation of the Polish case may provide novel scientific insights. First, the Polish market is particularly densely populated with very small firms. The average size of a company in our sample of December 2014 was only EUR 166 million. Over $50 \%$ of the companies listed on the Warsaw Stock Exchange had a capitalization of EUR 5.8 million or less, and almost $20 \%$ were smaller than EUR 1.2 million.

Second, the population of start-up companies in Poland is large and growing particularly rapidly. This trend was fuelled in 2007, when NewConnect, a special market for 
young, small start-up companies, was launched by Warsaw Stock Exchange (WSE). By the end of 2012, after a mere 5 years of operation, it has already become the second biggest start-up market in Europe. In fact, it is only outpaced by the London-based Alternative Investment Market, which is over 20 years old (Asygier, 2013).

Third, Polish investors may potentially display a particular tendency to invest in lottery-like stocks. Kumar (2009), based on data from a major US discount brokerage house, indicated that the strongest preference for lotterystock display poor, uneducated men who belong to, mainly Catholic, African-American or Hispanic minority. Firstly, these are factors common to people with the worst economic prospects within the American society, for whom lotteries and lottery stocks may be the only hope for gaining wealth. Poland is one of the poorest country in the European Union, which is a major reference point for people in Poland. ${ }^{1}$ As citizens of the EU, Polish investors may feel relatively poor, and that in turn, as we have already mentioned, may lead to the lottery preference. Secondly, Poland is a country with the highest percentage of Catholics within the EU (European Commission, 2012); therefore, it may also be more exposed to the lottery preference. It should be emphasized that the relation between religion and the tendency to lottery-type investment, which was observed by Kumar (2009), is not only an apparent correlation, resulting from the fact that majority of poor Americans are Catholics. Other researches showed that Catholics and Jews participate in lotteries more frequently than Protestants (Grichting, 1986). According to Clotfelter and Cook (1990), Catholics play about $50 \%$ more often than Protestants. Kumar et al. (2011) pointed out that this may be influenced by a much more strict attitude of Protestants towards gambling. Finally, the Polish stock market is basically an unexplored field in terms of low-price anomaly research. As far as we are aware, there is only one preliminary study carried out by (Zaremba \& Zmudzinski, 2014). This study is based on the most basic asset-pricing models and on short time-series of annual data. In effect, it yields inconclusive results.

The paper aims to contribute in a number of ways. First, this is the first comprehensive study of the low-price effect in Poland, which additionally employs state-of-the-art research methods. Second, we test for potential crosssectionally varying magnitude of the above mentioned phenomenon across various market segments. Finally, by introducing some novelties in the methods, we reexamine the catering hypothesis of Baker et al. (2009) within a fresh out-of-sample dataset.

The principal findings can be summarized as follows. Contrary to the international studies, we demonstrate a reverse low-price effect, which means that high-priced stocks significantly outperform the low-priced ones. The effect is particularly strong among the growth companies and slightly weakens when NewConnect companies are excluded from the sample. Moreover, we provide evidence that the relative performance of cheap stocks is correlated with the frequency of splits conducted by corporate managers.

\footnotetext{
${ }^{1}$ http://ec.europa.eu/eurostat/tgm/table.do?tab=table\&init=1 \&language $=e n \& p c o d e=t e c 00114 \&$ plugin $=1$ (accessed 14 March 2015).
}

The rest of the paper has the following structure: the next section contains the description of both the data and the methods; subsequently we present our research findings, and, in the last section, conclude our study.

\section{Related Literature}

Our study is related to two main strains of academic literature: on the low-price anomaly and on the lottery preferences in the stock market.

\section{Low-Price Anomaly}

The low-price effect is a stock anomaly that low priced shares significantly outperform high priced shares on a riskadjusted return basis. The phenomenon was firstly described by Fritzmeier (1936) on the US stocks market. He proved that low-priced stocks are associated with higher returns but also with higher risk. Subsequently, Allison and Heinds (1966) and Clenderin (1951) found that price risk was related to the low "quality" of stocks as perceived by investors rather that to low prices. In subsequent research, Blume and Husic (1973) confirmed the initial observations of Fritzmeier (1936) and scrutinized beta variability. Bachrach and Galai (1979) found that systematic risk did not fully explain the superior returns of cheaper stocks. Later, similar investigations were conducted by Christie (1982) and Dubofsky and French (1988), who decided to apply different risk measures. The superior performance of low-price stocks was also evidenced by Goodman and Peavy (1986). Branch and Chang (1990) associated the low-price effect with seasonal patterns on the stock market. Although the anomaly of the low-price effect has been widely described in the past, there are only a few recent studies in this respect. A notable example is the extensive research of Hwang and Lu (2008). The authors confirmed that stock returns are inversely related to nominal prices and demonstrated that the strategy of buying low price stocks can generate a significant alpha, even after considering the transaction costs.

In behavioral finance, the relative performance and valuation of low-price stocks is usually linked with the phenomenon of share splits. Yosef and Brown (1979), and later Strong (1983), noticed that the low price effect is valid for companies which split their shares. This is explained by the catering theory of nominal stock prices. According to Baker, Greenwood and Wurgler (2009), the theory predicts that when investors place higher valuations on low price firms, managers respond by supplying shares at lower price levels, and vice versa. The theory requires managers to believe that nominal prices matter to investors and gain motivation from evidence that key return characteristics are, in fact, affected by the nominal price. The splits will be more frequent when the valuations of low-priced firms are attractive relative to those of high-priced firms. The catering theory predicts splits to lower prices when lower price shares are favored.

\section{Lottery Stocks}

Similarly to lotteries, lottery stocks have very small probability of a large return. According to Kumar, some investors overvalue lottery-type assets. Investors are willing to accept negative expected value to buy a possibility of a 
big payoff. Kumar (2009) defined lottery stocks as a group of stocks with low prices, high variances and positively skewed returns. He found that the return of lottery-type stocks on the US market adjusted by annual risk is $-4,2 \%$. Similar relation was observed on Over-the-Counter markets in the US (Eraker \& Ready, 2013). It should be noted that a lottery payoff on an OTC market concerns start-up companies. Considering that most start-up companies go bankrupt and only a few are successful, it is self-evident that such companies are distinguished by high positive skewness of the return distribution. Thus, buying stocks of a start-up company might be treated by some investors as a lotterytype investment.

The phenomenon of lottery stocks and skewness preference is well explained on the basis of behavioral finance. Firstly, according to prospect theory (Kahneman \& Tversky, 1979), investors overvalue small and undervalue large probabilities. It could explain the popularity of lottery stocks whose prospects of big gains appear more attractive to investors. Secondly, behavioral portfolio theory (Shefrin \& Statman, 2000) assumes that the optimal portfolio resembles a two-layer pyramid. These two layers of the pyramid are associated with investors' aspirations. The main goal of a low aspiration level is to avoid poverty (bonds or other safe assets). A high aspiration level is designed to give a chance to become rich. This level consists of lottery-type assets.

\section{Methods}

This section describes both the research methods and data employed in this study. We begin with the description of our data sources, followed by a discussion of the examined portfolios and asset pricing tests. Finally, we explain our verification of the catering hypothesis.

\section{Playing field}

We use international stock returns and accounting data from Bloomberg, considering both listed and delisted companies in order to avoid any form of survivorship bias. ${ }^{2}$ Computations are based on monthly time-series as they provide us with a sufficient number of observations (177) to ensure the power of the conducted tests and allow us to avoid an excessive exposure to the micro-structure issues (De Moor \& Sercu, 2013). The returns are adjusted for corporate actions (splits, reverse splits, issuance rights, etc.) and cash distributions to investors (dividends). The sample period runs from April 2000 to December 2014; nonetheless, we also use earlier data where necessary to calculate a momentum factor (this issue is discussed in detail in the next subsection). The late start date was chosen deliberatery in order to avoid a small sample bias as well as to cover a significant number of companies. The sample encompasses stocks listed on the Warsaw Stock Exchange, including both NewConnect and non-NewConnect stocks. The precise number of firms in the sample increases from 66 in April 2000 to 855 in December 2014 while the time-series average is 363. A company is included in the sample in month $t$ when it is possible to retrieve its capitalization, book-to-market ratio and nominal share price at the end of

\footnotetext{
${ }^{2}$ The data were downloaded using equity screening function (EQS). We selected listed, delisted, liquidated, withdrawn and acquired companies.
}

month $t-1$ and its return in month $t$. All the prices and accounting data are denominated in Polish zlotys (PLN).

Finally, whenever we refer to the risk-free rate, we employ a mid-quote of the 1-month Warsaw Interbank Rate obtained from ACI The Financial Markets Association. ${ }^{3}$

\section{Tested Portfolios}

The study investigates the performance of portfolios from sorts on the nominal share price. Thus, in each month $t-1$, all stocks are ranked according to this metric. Next, for each characteristic, the $20^{\text {th }}, 40^{\text {th }}, 60^{\text {th }}$ and $80^{\text {th }}$ percentiles are defined as breakpoints and, thus, five subgroups are obtained. Finally, to form portfolios, the indices in the respective subgroups are weighted either equally or by capitalization. Additionally, we construct differential portfolios, which are synthetic zero-investment portfolios. These are basically long/short portfolios, which are $100 \%$ long in the quantile of markets with the highest prices and $100 \%$ short in the quantile of markets with the lowest prices.

Additionally, we are interested in identifying whether the price-return relationship is equally strong across stocks with various characteristics. Therefore, we divide the companies within our sample by their median (1) capitalization, (2) book-to-market ratio and (3) past return in months $t-12$ to $t$ - 2 . In these three cases, we obtain respectively: (1) large and small stocks, (2) growth and value stocks and (3) winner and loser stocks. Then, we form identical quantile portfolios as described above, but within the aforementioned subsets of the sample. Finally, we also examine the portfolio using NewConnects stocks, both those included and excluded from the sample. The reason is that NewConnect companies, due to their start-up nature, display strong lottery-like characteristics, so their exclusion may provide some additional insights.

\section{Performance evaluation}

The performance of quantile and zero-investment portfolios was examined using the four-factor model by Carhart (1997) based on the data from the Polish stock market. In other words, we have effectively tested whether the price-based stock selection strategies expand the frontier of an investor with an exposition to the market, value, size and momentum factor returns on the Polish market. These four effects are represented in the Carhart model by four respective asset pricing factors: market risk $(M k t-R f)$, high minus low $(H M L)$, small minus big $(S M B)$ and winners minus losers $(W M L) .{ }^{4}$ The model's corresponding equation is:

$$
\begin{aligned}
& \mathrm{R}_{\mathrm{i}, \mathrm{t}}=\alpha_{\mathrm{i}}+\mathrm{R}_{\mathrm{f}, \mathrm{t}}+\beta_{\mathrm{rm}, \mathrm{i}} \cdot\left(\mathrm{R}_{\mathrm{m}, \mathrm{t}}-\mathrm{R}_{\mathrm{f,t}}\right)+\beta_{\mathrm{SMB}, \mathrm{i}} \cdot \mathrm{SMB}_{t}+\beta_{\mathrm{HML}, \mathrm{i}} \cdot \\
& \mathrm{HML}_{t}+\beta_{\mathrm{WML}, \mathrm{i}} \cdot \mathrm{WML}_{t}+\varepsilon_{i, t},
\end{aligned}
$$$$
\text { where } \beta_{r m, i}, \beta_{S M B, i}, \beta_{H M L, i}, \beta_{W M L, i} \text {, and } \alpha_{i} \text { are the }
$$
estimated parameters of the model. $\beta_{r m, i}$ is analogical to the CAPM beta, but it is not equal to it. The $\beta_{S M B, i}, \beta_{H M L, i}$, and $\beta_{W M L, i}$ are exposures to $S M B$ (small minus big), $H M L$ (high minus low), and $W M L$ (winners minus losers) risk factors, respectively.

\footnotetext{
${ }^{3}$ Http://acipolska.pl/wibor/indeks-wibidwibor.html.

${ }^{4}$ The validity of the four-factor model for the Polish market was proven by Czapkiewicz and Wójtowicz (2014), Zaremba (2014), and Zaremba and Konieczka (2014).
} 
The market risk as calculated an excess return on the market portfolio formed from all stocks in the sample over the risk-free rate. In order to compute the three remaining classical cross-sectional factors $(H M L, S M B$, and $W M L)$, the stocks at time $t$-1were sorted on the $\mathrm{B} / \mathrm{M}$ ratio, size (a total stock market capitalization) and momentum (lagged stock cumulative return from time $t-12$ to $t-1)$. The explanatory factor returns were formed from $2 \times 3$ sorts on size and $\mathrm{B} / \mathrm{M}$ or size and momentum. Big stocks and small stocks were defined as those of the market value above and below the median at $t-1$. The $\mathrm{B} / \mathrm{M}$ breakpoints in the $2 \times 3$ sorts were the $30^{\text {th }}$ and $70^{\text {th }}$ percentiles of $\mathrm{B} / \mathrm{M}$ for all the stocks at $t-1$. The intersection of the independent $2 \times 3$ sorts on size and B/M produced six portfolios - $S G, S N, S V, B G, B N$, and $B V$, where $S$ and $B$ indicate small or big and $G, N$, and $V$ indicate growth, neutral, and value (bottom $30 \%$, middle $40 \%$, and top $30 \%$ of $\mathrm{B} / \mathrm{M})$, respectively. The next phase was to compute monthly value-weighted returns for all the six portfolios. Finally, the $t$-month return on the size factor, $S M B$, was calculated as the equal-weighted average of returns on the three small stock portfolios from the $2 \times 3$ size$\mathrm{B} / \mathrm{M}$ sorts minus the average of returns on the three big stock portfolios. The return on value factor, $H M L$, comprised the difference between equal-weighted returns on value portfolios $(B V, S V)$ and the equal-weighted average of the returns on growth portfolios $(B G, S G)$. The $2 \times 3$ sorts on size and momentum were performed in the same way as the size-B/M sorts, but with the lagged momentum return replacing $\mathrm{B} / \mathrm{M}$. For portfolios created at the end of month $t$ 1 , the lagged momentum return was the stock's cumulative return for the months $t-12$ to $t-2$. We followed Fama and French (2012) and skipped the sort month, which is the standard way of avoiding short-term reversal in momentum tests. The momentum breakpoints were used to construct a two by three matrix, identical to that for $H M L$. The $W M L$ return in month $t$ was computed as the difference between the equal-weighted average of the returns on small and large winner stocks $(S W, B W)$ and the equal-weighted average of returns on small and big loser stocks $(S L, B L)$.

Following Fama and French (2012), all the regression parameters were estimated using the OLS regressions, in line with the remarks of Cochrane (2001), who regards this method as usually more robust than for example GLS. Furthermore, t-statistics corresponding to the parameters were estimated using bootstrap standard errors, so as not to take any distributional assumptions. In order to find whether the intercepts in a group of portfolios statistically differ from 0 , they were evaluated with the common GRS test statistic, as suggested by Gibbons et al. (1989):

$$
\begin{aligned}
& G R S= \\
& \left(\frac{T}{N}\right) \times\left(\frac{T-N-L}{T-L-1}\right) \times \hat{\alpha}^{\widehat{I}^{-1}} \widehat{\alpha} \times\left[1+E_{T}(f)^{\prime} \hat{\Omega}^{-1} E_{T}(f)\right]^{-1} \sim F_{N, T-N-K},
\end{aligned}
$$

where $T$ is the length of the time-series (sample size), $N$ is the number of portfolios to be explained in the examined group and $L$ denotes the number of explanatory factors. $E_{T}(f)$ is a vector of expected returns on asset pricing factors (estimated as a simple average over the investigated period - see Cochrane 2005, p. 231), $\hat{\Omega}$ is a covariance matrix of the asset pricing factors, $\hat{\alpha}$ is a vector of regression intercepts and $\hat{\Sigma}$ is a residual covariance matrix in the sample. The test's critical values are obtained from the Fisher's distribution with $N$ and $T-N-L$ degrees of freedom. The null hypothesis assumes that all the intercepts (five) are equal to 0 , with the alternative hypothesis assuming the contrary.

One of the weaknesses of the GRS test statistic is that it simply indicates that some of the portfolios in a given set significantly outperform, but does not consider the structure or monotonicity. Therefore, so as to test whether the excess return (intercepts) are systematically increasing or decreasing with the changes of the underlying variable, we also carried out a monotonic relation (MR) test introduced by Patton and Timmermann (2010). This is a simulationbased test, where the basic hypothesis says that there is no monotonic pattern in excess returns (intercepts), with an alternative hypothesis that such pattern exists. The precise testing procedure is described in a paper by Patton and Timmerman (2010). Each MR test in this paper was based on 10.000 random draws, and applied to both the raw excess returns and intercepts from the asset pricing models.

\section{Examination of the Catering Hypothesis}

Finally, we examined whether the performance of lowand high-priced stocks was somehow related to the propensity of corporate managers splitting shares of their companies and, thus, catering to investors with nominal share prices. To this end, we initially calculated the percentage of companies which split their shares in particular years. ${ }^{5}$ Next, we compared this metric with the relative pricing of low- and high-price stocks. Nonetheless, we introduced here a certain measuring innovation. In their groundbreaking research on catering through nominal share prices, Baker et al. (2009) had introduced a "low-price premium" as a metric of relative attractiveness of cheap stocks as perceived by corporate managers. These authors had used a log difference in the average market-to-book ratios of low- and high-priced stocks. In other words, the authors had assumed that the market-to-book ratio was a good proxy of the "high" or "low" valuation of stocks. Nonetheless, the same authors in their subsequent publication admitted that employing this metric as a proxy for over- or undervaluation posed significant theoretical and empirical challenges (Baker et al., 2007). In general, the cross-sectional variation in market-to-book ratios may stem from an array of company characteristics. In fact, some authors strongly reject the concept of linking this metric to over- or undervaluation and argue that its values are rather related to cross-sectionally varying risk. ${ }^{6}$

Therefore, in this paper we refrained from any concepts related to misvaluation. In opposition to this approach, we simply assumed that corporate managers react to relative past performance of low- and high-priced stocks. In other words, when managers observe that cheap stocks perform particularly well, they are more prone to splitting shares than after periods of observed underperformance. Thus, we introduced a cheap-stock premium as the return on a zerocost long/short portfolio, which is long in the quintile of low-priced stocks and short in the quintile of high-priced stocks. Strictly speaking, the cheap-stock premium equals a

\footnotetext{
${ }^{5}$ The list of splits is retrieved from the Brokerage House of the Bank for Environmental Protection (http://bossa.pl/analizy/splity/, accessed 20 February 2015).

${ }^{6}$ For further information please look for example at Fama and French (1993, 1995), Lakonishok, Schleifer and Vishny (1994),
} 
short position within the zero-investment portfolio described in the section "Tested portfolios". To assure reliability of the results, we used four variations of the cheap-stock premium (equally or capitalization-weighted with NewConnect stocks included or excluded). Furthermore, we used five distinct periods of past performance evaluation: 1, 2, 3, 4 and 5 years.

We adopted two simple correlation metrics to examine the relationship between frequency of splits in year $t$ and the past cheap-stock premium in years $t-5$ to $t-1$. The basic measure was simple Spearman's rank correlations (Spearman, 1904), which we supplemented with Pearson's product-moment correlations (Pearson, 1920). It is important to stress out that our basic measure is Spearman's rank correlation. The Pearson correlation is not entirely appropriate here because the frequency of splits is certainly non-normally distributed. Therefore, this measure should be regarded as a supplementary metric, which is employed to verify the robustness of the outcomes.

For the both measures, we examined a null hypothesis stating that correlation coefficients are equal to 0 , with the alternative hypothesis to the contrary. The test statistics were calculated using Fisher transformation (Fieler et al., 1957; Choi, 1977).

\section{Results and Discussion}

In this section, we first discuss the performance of portfolios weighted equally and by capitalization from the sorts on prices. Next, we present further statistics on portfolios formed on double-sorts, first on value, size and momentum metrics, and then on prices. Finally, we provide evidence on catering to investors with nominal share prices.

\section{Price-Return Relation}

Table 1 reports performance of equally and capitalization-weighted portfolios formed on nominal prices. The first glimpse at outcomes of the analysis of the equally-weighted portfolios (Table 1, panel A) seemingly confirms the low-prices effect, with negative returns significantly different from 0 on the zero-investment portfolio reaching $-1,21 \%$ monthly and a rejected GRS test hypothesis. Nonetheless, this picture can be misleading. First, the intercept of the zero-investment portfolio from the four-factor model is close to zero, which indicates that the entire outwardly abnormal return can be fully explained by the market, value, size and momentum factors. Second, the performance of equally-weighted portfolios could be distorted by the so-called returns on diversification (Willenbrock, 2011). As a result of this phenomenon, systematic rebalancing becomes a significant source of additional alpha. In fact, this effect is evident in the research discussed here, as all the quintile portfolios have positive intercepts from the four factor model and four of them are significantly different from 0 . The examination of capitalization-weighted portfolios (Table 1, panel B) is additionally more meaningful from the investor's perspective, because it is not skewed towards small and illiquid companies.

Excess returns on portfolios from sorts on prices (full sample)

\begin{tabular}{|c|c|c|c|c|c|c|c|c|}
\hline & Low & 2 & 3 & 4 & High & High-Low & MR & GRS \\
\hline \multicolumn{9}{|c|}{ Panel A: equal-weighted portfolios } \\
\hline \multirow[t]{2}{*}{ Mean } & $1.29 *$ & 0.13 & 0.59 & 0.47 & 0.43 & $-1.21 * *$ & 100.0 & \\
\hline & $(1.74)$ & $(0.13)$ & $(0.93)$ & $(0.75)$ & $(0.65)$ & $(-2.70)$ & & \\
\hline Standard deviation & 8.64 & 7.91 & 7.23 & 6.60 & 6.82 & 6.34 & & \\
\hline Skewness & 0.48 & 0.09 & 0.10 & -0.23 & -0.26 & -1.82 & & \\
\hline \multirow[t]{2}{*}{ Intercept } & $0.61 *$ & 0.11 & $0.67 * *$ & $0.52 * *$ & $0.77 * *$ & -0.04 & 21.9 & 1.02 \\
\hline & $(1.79)$ & $(0.37)$ & $(2.41)$ & $(2.13)$ & $(3.38)$ & $(-0.10)$ & & \\
\hline \multicolumn{9}{|c|}{ Panel B: capitalization-weighted portfolios } \\
\hline \multirow[t]{2}{*}{ Mean } & -0.95 & $-1.31 * *$ & 0.15 & -0.33 & 0.06 & $0.75^{*}$ & 52.7 & \\
\hline & $(-1.56)$ & $(-2.26)$ & $(0.11)$ & $(-0.73)$ & $(-0.01)$ & $(1.68)$ & & \\
\hline Standard deviation & 7.98 & 8.11 & 7.66 & 6.80 & 7.16 & 6.12 & & \\
\hline Skewness & -0.13 & -0.41 & -0.35 & -0.47 & -0.59 & -0.33 & & \\
\hline \multirow{2}{*}{ Intercept } & $-0.74 *$ & $-0.93 * *$ & 0.55 & -0.20 & 0.31 & $0.82 *$ & 66.4 & 2.97 \\
\hline & $(-1.67)$ & $(-2.42)$ & $(1.60)$ & $(-0.71)$ & (1.51) & (1.71) & & \\
\hline
\end{tabular}

Notes. The table reports means, standard deviations, skewness and intercepts from the four-factor model of excess returns on quintile portfolios sorted on market prices. "Low" denotes stocks with the lowest prices and "High" with the highest prices. "High-Low" is a zero-cost portfolio, which is long in the high-price stocks and short in the low-price stocks. MR and GRS are $p$ values from MR (Patton and Timmerman, 2010) and GRS (Gibbons $e t$ al., 1989) tests. The means, standard deviations, intercepts and $p$-values are expressed as percentages. The numbers in brackets are $t$-statistics and the significance at $10 \%$ level is in bold type. * and ** indicate values significantly different from 0 at $10 \%$ and $5 \%$ level, respectively.

Interestingly, the results of investigations of capweighted portfolios contradict observations from international markets. Although the MR test detected no evident monotonicity in return patterns, the excess returns and intercepts suggest a reverse low-price premium. The two portfolios containing stocks with the lowest prices have negative alphas that are significantly different from 0 and equal to $-0,74 \%$ and $-0,93 \%$. Furthermore, the zero-cost portfolio delivers positive and significant abnormal returns while the $p$-value for the GRS test is equal to $2,97 \%$.

These results are different from the observations made for other markets. For example, Hwang and Lu (2008) have shown that for a price-based portfolio of US stocks, low-share price stocks have higher average returns than high-price stocks. The authors adopted a strategy of buying low price stocks and selling high price stocks that generated significant positive returns even after considering the transaction costs.

Interestingly, all capitalization-weighted portfolios formed on prices have left-skewed return distributions; however, it is the cheapest stocks portfolio that displays skewness closest to 0 . This observation corresponds in some way to the concept of lottery-stocks. The smallest negative skewness of portfolio with the lowest prices may suggest 
that low price stocks often meet also other conditions of lottery stocks. Due to the idiosyncratic risk reduction, skewness on the level of indices is usually negative, even when skewness of particular stocks is positive (Albuquerqe, 2012). Bigger positive skewness on particular stocks is one of the distinctive features of lottery stocks.

The outcomes of double-sorts displayed in Table 2 provide additional insights into sources of the anomalous character of the low-price anomaly on the Polish stock market. The crucial factor here are growth companies. Anomalies related to price are particularly strong in these companies, as is the positive relation between the nominal share prices and expected returns. The negative abnormal returns on low-price stocks are very large (-2,43\% monthly) and highly significant. Partially as a result of that excess, returns and intercepts of the zero-investment portfolios are both significant and positive. Furthermore, the MR test suggests clear monotonicity in the relation between returns and nominal share prices and the GRS test hypothesis is strongly rejected.

Moreover, the reverse low-price anomaly is stronger for loser companies. The excess returns and alphas on the lowprice quintile portfolios are markedly negative and the pattern of excess returns is significantly monotonic. Finally, large companies also seem relatively interesting, with significant excess and abnormal negative returns on the cheapest stocks, significant positive alphas and excess returns on the zero-investment portfolio. Nevertheless, neither the MR nor the GRS test hypotheses are rejected in this case.

The performance of portfolios from sorts on prices in the remaining subsets of stocks - small, value and winner companies - are predominantly inconclusive. Although excess returns on zero-investment portfolios are mostly negative, they are neither significantly different from 0 nor fully explained by the four-factor model.

Other researches present high associations between share price and other factors. For example, Hwang and $\mathrm{Lu}$ (2008) provided evidence that profitability of a low-price stocks based portfolio was robust in the presence of other effects. The authors showed that for the two dimensional sorts, the price strategy of long penny and short high price stocks was profitable even after controlling the effects of size, book-to-market, momentum and earning /price.

Most of our results are consistent with the conclusions regarding lottery stocks. By definition, among low prices, high volatility is one feature of lottery stocks. Considering high volatility and skewness of our penny portfolio, we can assume that many of these stocks satisfy the condition of lottery stocks. This assumption is also supported by other characteristics of lottery stocks and our findings. As Kumar (2009) observed: most of lottery stocks comprised growth company. An average $\mathrm{B} / \mathrm{M}$ for the lottery-type group of stocks was 0.253 . It is consistent with our findings.

Table 2

Excess returns on portfolios from double sorts on prices and additional variables (full sample)

\begin{tabular}{|c|c|c|c|c|c|c|c|c|}
\hline & Low & 2 & 3 & 4 & High & High-Low & MR & GRS \\
\hline \multicolumn{9}{|c|}{ Large companies } \\
\hline \multirow[t]{2}{*}{ Mean } & $-1.12 * *$ & -0.06 & -0.77 & 0.09 & 0.04 & $0.94 * *$ & 81.9 & \\
\hline & $(-1.97)$ & $(-0.23)$ & $(-1.39)$ & $(0.01)$ & $(-0.03)$ & $(2.51)$ & & \\
\hline Standard deviation & 8.18 & 7.70 & 7.31 & 7.12 & 7.29 & 5.35 & & \\
\hline Skewness & -0.29 & -0.65 & -0.54 & -0.57 & -0.59 & -0.02 & & \\
\hline \multirow[t]{2}{*}{ Intercept } & $-0.81 * *$ & 0.12 & -0.60 & 0.33 & 0.22 & $0.79 *$ & 71.7 & 24.75 \\
\hline & $(-1.96)$ & $(0.40)$ & $(-1.55)$ & $(1.09)$ & $(0.98)$ & $(1.74)$ & & \\
\hline \multicolumn{9}{|c|}{ Small companies } \\
\hline \multirow[t]{2}{*}{ Mean } & 0.16 & 0.09 & -0.38 & 0.64 & 0.80 & -0.19 & 40.1 & \\
\hline & $(0.07)$ & $(0.11)$ & $(-0.59)$ & $(0.91)$ & $(1.26)$ & $(-0.19)$ & & \\
\hline Standard deviation & 10.66 & 8.80 & 9.20 & 8.31 & 7.43 & 10.91 & & \\
\hline Skewness & 1.22 & 0.43 & 0.32 & 0.18 & 0.12 & -4.00 & & \\
\hline \multirow[t]{2}{*}{ Intercept } & -0.79 & 0.35 & -0.54 & 0.48 & 0.75 & 0.94 & 29.2 & 15.35 \\
\hline & $(-1.38)$ & $(0.57)$ & $(-1.37)$ & $(0.97)$ & (1.79) & $(1.04)$ & & \\
\hline \multicolumn{9}{|c|}{ Value companies } \\
\hline \multirow[t]{2}{*}{ Mean } & 0.53 & -0.46 & 0.25 & 0.90 & 0.43 & -0.75 & 78.2 & \\
\hline & $(0.55)$ & $(-0.75)$ & $(0.26)$ & $(1.26)$ & $(0.61)$ & $(-0.96)$ & & \\
\hline Standard deviation & 10.14 & 9.46 & 8.23 & 8.89 & 7.97 & 9.51 & & \\
\hline Skewness & 0.49 & 0.00 & -0.60 & 0.10 & 0.04 & -1.22 & & \\
\hline \multirow[t]{2}{*}{ Intercept } & 0.17 & 0.15 & 0.34 & -0.10 & -0.22 & -0.80 & 12.9 & 95.39 \\
\hline & $(0.26)$ & $(0.33)$ & $(0.70)$ & $(-0.17)$ & $(-0.71)$ & $(-1.05)$ & & \\
\hline \multicolumn{9}{|c|}{ Growth companies } \\
\hline \multirow[t]{2}{*}{ Mean } & $-1.93 * *$ & -0.81 & -0.93 & -0.11 & 0.06 & $1.47 * *$ & 5.0 & \\
\hline & $(-2.79)$ & $(-1.34)$ & $(-1.56)$ & $(-0.34)$ & $(0.00)$ & $(2.65)$ & & \\
\hline Standard deviation & 9.24 & 8.28 & 7.67 & 7.41 & 6.94 & 7.93 & & \\
\hline Skewness & 0.01 & 0.00 & -0.93 & -0.34 & -0.80 & -1.03 & & \\
\hline \multirow[t]{2}{*}{ Intercept } & $-2.43 * *$ & 0.05 & $-0.77 *$ & 0.00 & 0.36 & $2.35 * *$ & 17.6 & 0.03 \\
\hline & $(-4.00)$ & $(0.12)$ & $(-1.83)$ & $(0.02)$ & $(1.37)$ & $(3.38)$ & & \\
\hline \multicolumn{9}{|c|}{ Winner companies } \\
\hline \multirow[t]{2}{*}{ Mean } & 0.26 & 0.58 & 0.11 & 0.28 & 0.01 & -0.64 & 42.0 & \\
\hline & $(0.31)$ & $(0.73)$ & $(0.07)$ & $(0.43)$ & $(-0.16)$ & $(-1.16)$ & & \\
\hline Standard deviation & 8.42 & 8.31 & 8.01 & 7.19 & 7.96 & 8.44 & & \\
\hline Skewness & 0.25 & -0.68 & 0.16 & -0.43 & -0.62 & -1.20 & & \\
\hline \multirow[t]{2}{*}{ Intercept } & -0.77 & -0.10 & -0.04 & -0.08 & 0.07 & 0.59 & 1.5 & 83.40 \\
\hline & $(-1.36)$ & $(-0.14)$ & $(-0.06)$ & $(-0.24)$ & $(0.16)$ & $(0.92)$ & & \\
\hline
\end{tabular}




\begin{tabular}{|c|c|c|c|c|c|c|c|c|}
\hline & Low & 2 & 3 & 4 & High & High-Low & MR & GRS \\
\hline \multicolumn{9}{|c|}{ Loser companies } \\
\hline Mean & $\begin{array}{c}-1.59 * * \\
(-2.18)\end{array}$ & $\begin{array}{l}-1.68 * * \\
(-2.01)\end{array}$ & $\begin{array}{l}-1.20^{*} \\
(-1.93)\end{array}$ & $\begin{array}{c}-0.76 \\
(-1.10)\end{array}$ & $\begin{array}{c}-0.72 \\
(-1.25)\end{array}$ & $\begin{array}{c}0.29 \\
(0.46)\end{array}$ & 4.0 & \\
\hline Standard deviation & 9.94 & 10.73 & 9.09 & 8.67 & 8.01 & 9.08 & & \\
\hline Skewness & 0.21 & -0.51 & -0.39 & -0.56 & -0.32 & -0.82 & & \\
\hline Intercept & $\begin{array}{l}-0.97^{*} \\
(-1.68)\end{array}$ & $\begin{array}{l}-1.09 * \\
(-1.70)\end{array}$ & $\begin{array}{c}-0.75 \\
(-1.43)\end{array}$ & $\begin{array}{c}0.43 \\
(1.08)\end{array}$ & $\begin{array}{c}-0.07 \\
(-0.23)\end{array}$ & $\begin{array}{c}0.44 \\
(0.56)\end{array}$ & 12.3 & 14.85 \\
\hline
\end{tabular}

Notes. The table reports means, standard deviations, skewness and intercepts from the four-factor model of excess returns on capitalization-weighted quintile portfolios sorted on market prices. "Low" denotes stocks with the lowest prices and "High" with the highest prices. "High-Low" is a zero-cost portfolio, which is long in the high-price stocks and short in the high-price stocks. MR and GRS are $p$-values from MR (Patton and Timmerman, 2010) and GRS (Gibbons et al., 1989) tests. The means, standard deviations, intercepts and $p$-values are expressed as percentages. The numbers in brackets are $t$-statistics and the significance at $5 \%$ level is in bold type. * and ** indicate values significantly different than 0 at $10 \%$ and $5 \%$ level, respectively. The large/small, value/growth and winner/loser distinctions are made based on a median stock capitalization, B/M ratio and past 12-month performance respectively.

On the other hand, we noticed a stronger low-price effect among large companies. This finding may seem to be inconsistent with Kumar's studies. His average lottery stock was rather a small company. It suggests that for some reasons an average lottery-type company in Poland is relatively bigger than the one on the US market. We can only suspect the reason. The first explanation is that sector structure of the Polish market differs from the US market while in Poland a number of lottery-feature companies are medium or large cap. The second explanation points to the different period of the researches. While Kumar conducted his researches during the bull market (1991-1996), our research period includes the last financial crisis. A possible serious crash on the stock market could both influence the market and induce lottery feature also among large companies. Finally, the stock market companies in Poland are simply much smaller than their counterparts in the USA. In other words, what is large in Poland, could be still classified as small overseas.

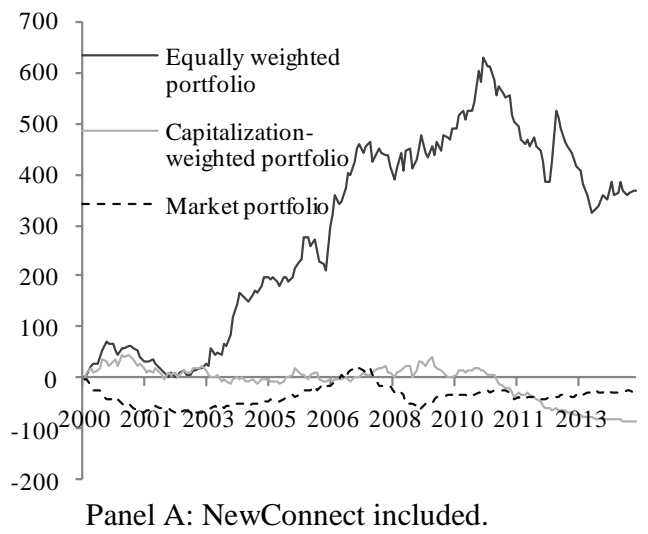

Finally, the cumulative returns on the zero-cost portfolios weighted equally and by capitalization are depicted in panel A of Figure 1. In this case, in order to make our results more comparable to the outcomes of Baker et al. (2009), we present the performance of the zero-cost long/short portfolios, which assume long positions in the cheap stocks and short positions in the expensive stocks (the reverse of the zero-cost portfolios in Tables 1-4). Further on, we refer to the return on the zeroinvestment portfolio as the cheap-stock premium (contrary to the low-price premium of Baker et al., 2009). The cheap-stock premium is time-varying and unstable. As regards equally weighted portfolios, the returns were positive until 2010 and then started to decline. The behavior of capitalization-weighted portfolios is similar, but the excess returns are much closer to 0 . The strategy's performance reaches its peak in early 2009 and then steadily declines below 0 .

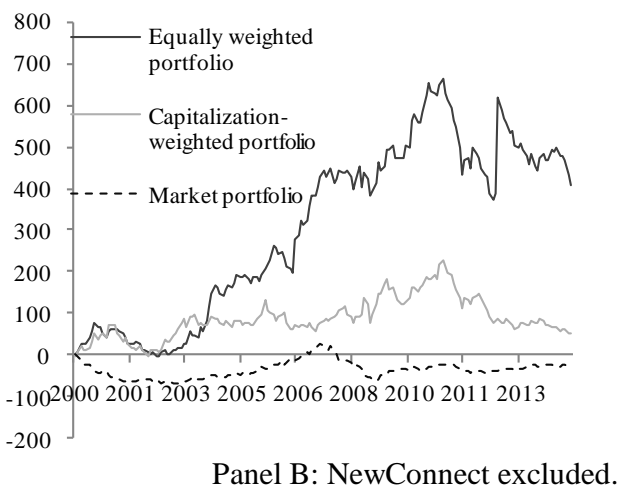

Figure 1. Performance of zero-investment portfolios from sorts on prices

Notes. The figure presents cumulative returns on zero-cost long/short portfolios, which are long in the low-price stocks and short in the high-price stocks. The performance is compared with the cumulative excess returns on the market portfolio (capitalization-weighted mean of returns on all the stocks in the sample).

The combined concentration of reverse low-price effect in the segment of growth companies and the reversal of the cheap-stock premium after the year 2009 suggests that some responsibility may be ascribed to the NewConnect stocks. The NewConnect market was launched in 2009 and it was around the turn of 2009 and 2010 that it started to play a significant role. Moreover, due to its character as a market for start-up companies, the firms listed on NewConnect resemble the lottery-like stocks.

Indeed, when the NewConnect stocks are excluded, the reverse low-price effect not only weakens, but disappears entirely (Table 3 ). The excess return and alpha on the zero-investment portfolio are not significantly different from 0 (and even slightly negative). Moreover, although the intercept from the quintile portfolio containing stocks with the second-lowest prices is significantly negative, it is not sufficient to reject the GRS hypothesis. On the other hand, equally-weighted portfolios reveal performance that is quite similar to the sample including the NewConnect stocks. To summarize, the investigations of non-NewConnect stocks remain inconclusive and provide no evidence supporting either the low- or reverse low-price anomaly. 
Excess returns on portfolios from sorts on prices (NewConnect excluded)

Table 3

\begin{tabular}{|c|c|c|c|c|c|c|c|c|}
\hline & Low & 2 & 3 & 4 & High & High-Low & MR & GRS \\
\hline \multicolumn{9}{|c|}{ Equally-weighted portfolios } \\
\hline \multirow[t]{2}{*}{ Mean } & 1.35 & 0.36 & 0.42 & 0.46 & 0.47 & $-1.43 * *$ & 98.2 & \\
\hline & $(1.59)$ & $(0.47)$ & $(0.59)$ & $(0.71)$ & $(0.71)$ & $(-2.41)$ & & \\
\hline Standard deviation & 9.57 & 7.92 & 7.47 & 6.63 & 6.97 & 8.12 & & \\
\hline Skewness & 0.67 & 0.18 & -0.01 & -0.06 & -0.31 & -3.63 & & \\
\hline Intercept & $\begin{array}{c}0.38 \\
(0.82)\end{array}$ & $\begin{array}{c}0.05 \\
(0.19)\end{array}$ & $\begin{array}{c}0.11 \\
(0.44)\end{array}$ & $\begin{array}{c}0.17 \\
(0.65)\end{array}$ & $0.54 * *$ & $\begin{array}{c}-0.24 \\
(-0.40)\end{array}$ & 6.6 & 42.43 \\
\hline \multicolumn{9}{|c|}{ Capitalization-weighted portfolios } \\
\hline \multirow[t]{2}{*}{ Mean } & 0.40 & $-0.93 *$ & -0.05 & -0.23 & 0.08 & -0.64 & 98.0 & \\
\hline & $(0.45)$ & $(-1.80)$ & $(-0.21)$ & $(-0.60)$ & $(0.03)$ & $(-1.18)$ & & \\
\hline Standard deviation & 8.58 & 7.90 & 7.78 & 6.56 & 7.52 & 6.92 & & \\
\hline Skewness & 0.30 & -0.88 & -0.47 & -0.36 & -0.56 & -0.78 & & \\
\hline \multirow[t]{2}{*}{ Intercept } & 0.09 & -0.80 ** & 0.34 & -0.31 & 0.23 & -0.17 & 60.0 & 22.38 \\
\hline & $(0.16)$ & $(-2.17)$ & $(1.00)$ & $(-1.08)$ & $(1.02)$ & $(-0.30)$ & & \\
\hline
\end{tabular}

Notes. The table reports means, standard deviations, skewness and intercepts from the four-factor model of excess returns on the quintile portfolios sorted on the market prices. "Low" denotes stocks with the lowest prices and "High" with the highest prices. "High-Low" is a zero-cost portfolio, which is long in the high-price stocks and short in the high-price stocks. MR and GRS are $p$-values from MR (Patton and Timmerman, 2010) and GRS (Gibbons et al., $1989)$ tests. The means, standard deviations, intercepts and $p$-values are expressed as percentages. The numbers in brackets are $t$-statistics and the significance at $10 \%$ level is in bold type. $*$ and $* *$ indicate values significantly different from 0 at $10 \%$ and $5 \%$ level, respectively.

The time-series variation of the cheap-stock premium for the sample excluding the NewConnect stocks (Figure 1, panel B) is to some extent similar to the full sample. The cumulative excess returns on equally-weighted portfolios are still considerably large, but fully explained by the fourfactor model, as can be seen in the Table 3. On the contrary, the cumulative excess returns on the capitalization-weighted zero-investment portfolio turn out to be positive, but very low (Figure 1, panel B). Finally, sizeable time-variation in returns can still be observed with a characteristic peak in the years 2009-2010. This pattern suggests that although the exclusion of the NewConnect stocks significantly altered the return pattern of capitalization-weighted portfolios, the significant timevariation of returns has not been erased. Apparently, not only NewConnect stocks were responsible.

Table 4

Excess returns on portfolios from double sorts on prices and additional variables (NewConnect excluded)

\begin{tabular}{|c|c|c|c|c|c|c|c|c|}
\hline & Low & 2 & 3 & 4 & High & High-Low & MR & GRS \\
\hline \multicolumn{9}{|c|}{ Large companies } \\
\hline \multirow[t]{2}{*}{ Mean } & -0.14 & -0.10 & -0.73 & 0.01 & 0.16 & 0.14 & 74.9 & \\
\hline & $(-0.44)$ & $(-0.26)$ & $(-1.38)$ & $(-0.16)$ & $(0.18)$ & $(0.45)$ & & \\
\hline Standard deviation & 7.56 & 7.75 & 7.07 & 7.54 & 7.60 & 5.60 & & \\
\hline Skewness & -0.26 & -0.38 & -0.54 & -0.51 & -0.52 & -0.34 & & \\
\hline \multirow[t]{2}{*}{ Intercept } & -0.09 & 0.11 & $-1.01 * *$ & 0.31 & 0.22 & 0.13 & 85.0 & 10.28 \\
\hline & $(-0.27)$ & $(0.39)$ & $(-2.66)$ & (1.04) & $(0.87)$ & $(0.28)$ & & \\
\hline \multicolumn{9}{|c|}{ Small companies } \\
\hline \multirow[t]{2}{*}{ Mean } & 0.75 & 0.49 & 0.42 & 0.90 & 0.70 & -0.72 & 16.0 & \\
\hline & $(0.74)$ & $(0.62)$ & $(0.43)$ & $(1.22)$ & (1.09) & $(-1.05)$ & & \\
\hline Standard deviation & 10.57 & 9.16 & 9.44 & 8.76 & 7.30 & 8.80 & & \\
\hline Skewness & 0.80 & 0.04 & 0.08 & 0.28 & 0.13 & -1.89 & & \\
\hline \multirow[t]{2}{*}{ Intercept } & -0.18 & 0.28 & -0.07 & 0.39 & 0.37 & 0.01 & 9.2 & 81.58 \\
\hline & $(-0.35)$ & $(0.58)$ & $(-0.24)$ & $(0.91)$ & $(1.03)$ & $(-0.02)$ & & \\
\hline \multicolumn{9}{|c|}{ Value companies } \\
\hline \multirow[t]{2}{*}{ Mean } & 0.75 & 0.45 & 0.05 & 0.52 & 0.43 & -0.96 & 20.4 & \\
\hline & $(0.76)$ & $(0.44)$ & $(0.01)$ & $(0.76)$ & $(0.61)$ & $(-1.24)$ & & \\
\hline Standard deviation & 10.32 & 9.80 & 8.08 & 9.06 & 8.10 & 9.51 & & \\
\hline Skewness & 0.28 & 0.31 & -0.83 & 0.00 & 0.09 & -1.46 & & \\
\hline \multirow[t]{2}{*}{ Intercept } & 0.16 & 0.63 & -0.35 & -0.03 & -0.01 & -0.69 & 50.0 & 85.70 \\
\hline & $(0.27)$ & $(1.18)$ & $(-0.68)$ & $(-0.05)$ & $(-0.15)$ & $(-1.04)$ & & \\
\hline \multicolumn{9}{|c|}{ Growth companies } \\
\hline \multirow[t]{2}{*}{ Mean } & $-2.17 * *$ & -0.50 & -0.22 & -0.29 & 0.08 & $1.74 * *$ & 3.1 & \\
\hline & $(-3.03)$ & $(-0.91)$ & $(-0.44)$ & $(-0.64)$ & $(0.03)$ & $(3.01)$ & & \\
\hline Standard deviation & 9.33 & 8.21 & 7.44 & 7.68 & 7.55 & 8.17 & & \\
\hline Skewness & -0.17 & -0.51 & -0.71 & -0.56 & -0.70 & -0.68 & & \\
\hline \multirow[t]{2}{*}{ Intercept } & $-2.33 * *$ & -0.28 & -0.42 & -0.13 & 0.19 & $1.97 * *$ & 2.8 & 0.24 \\
\hline & $(-4.14)$ & $(-0.67)$ & $(-1.01)$ & $(-0.44)$ & $(0.70)$ & $(2.95)$ & & \\
\hline \multicolumn{9}{|c|}{ Winner companies } \\
\hline \multirow[t]{2}{*}{ Mean } & $1.15^{*}$ & 0.33 & 0.57 & 0.08 & 0.16 & $-1.36 * *$ & 76.5 & \\
\hline & $(1.76)$ & $(0.37)$ & $(0.85)$ & $(0.02)$ & $(0.11)$ & $(-2.24)$ & & \\
\hline Standard deviation & 8.44 & 8.30 & 7.84 & 7.18 & 8.34 & 8.42 & & \\
\hline
\end{tabular}




\begin{tabular}{|c|c|c|c|c|c|c|c|c|}
\hline & Low & 2 & 3 & 4 & High & High-Low & MR & GRS \\
\hline Skewness & 0.26 & -0.50 & 0.16 & -0.50 & -0.63 & -0.82 & & \\
\hline Intercept & $\begin{array}{c}0.17 \\
(0.28) \\
\end{array}$ & $\begin{array}{c}-0.36 \\
(-0.69) \\
\end{array}$ & $\begin{array}{c}0.11 \\
(0.23) \\
\end{array}$ & $\begin{array}{c}-0.32 \\
(-0.98) \\
\end{array}$ & $\begin{array}{c}0.24 \\
(0.64) \\
\end{array}$ & $\begin{array}{c}-0.14 \\
(-0.28) \\
\end{array}$ & 12.1 & 81.65 \\
\hline \multicolumn{9}{|c|}{ Loser companies } \\
\hline Mean & $\begin{array}{c}-0.48 \\
(-0.73)\end{array}$ & $\begin{array}{c}-0.98 \\
(-1.16)\end{array}$ & $\begin{array}{l}-1.06 \\
(-1.37)\end{array}$ & $\begin{array}{c}-0.71 \\
(-1.07)\end{array}$ & $\begin{array}{c}-0.61 \\
(-1.12)\end{array}$ & $\begin{array}{c}-0.59 \\
(-0.80)\end{array}$ & 35.6 & \\
\hline Standard deviation & 9.29 & 10.97 & 10.32 & 8.53 & 8.17 & 8.54 & & \\
\hline Skewness & 0.34 & -0.55 & -1.55 & -0.53 & -0.28 & -1.23 & & \\
\hline Intercept & $\begin{array}{c}-0.69 \\
(-1.47) \\
\end{array}$ & $\begin{array}{c}-0.70 \\
(-1.28) \\
\end{array}$ & $\begin{array}{c}-0.61 \\
(-1.17) \\
\end{array}$ & $\begin{array}{c}-0.08 \\
(-0.22) \\
\end{array}$ & $\begin{array}{c}-0.41 \\
(-1.00) \\
\end{array}$ & $\begin{array}{c}-0.05 \\
(-0.08) \\
\end{array}$ & 4.1 & 31.39 \\
\hline
\end{tabular}

Notes. The table reports means, standard deviations, skewness and intercepts from the four-factor model of excess returns on the capitalization-weighted quintile portfolios sorted on the market prices. "Low" denotes stocks with the lowest prices and "High" with the highest prices. "High-Low" is a zerocost portfolio, which is long in the high-price stocks and short in the high-price stocks. MR and GRS are $p$-values from MR (Patton and Timmerman, 2010) and GRS (Gibbons et al., 1989) tests. The means, standard deviations, intercepts and $p$-values are expressed as percentages. The numbers in brackets are $t$-statistics and the significance at $5 \%$ level is in bold type. $*$ and $* *$ indicate values significantly different from 0 at $10 \%$ and $5 \%$ level, respectively. The large/small, value/growth and winner/loser distinctions are made based on the median stock capitalization, B/M ratio and the past 12month performance, respectively.

Table 4 provides further insights on the performance of low- and high price strategies after exclusion of the NewConnect stocks. Actually, most of the significant abnormal returns detected in the market segments where the full sample was adopted disappeared. The GRS tests are no longer rejected for loser or large companies, and they are still not rejected for small, value or winner companies. However, the behavior of growth stocks still remains anomalous. In this market segment, expensive stocks significantly outperform cheap stocks. The MR tests confirm monotonicity and the GRS tests indicate to a significant expansion of the efficient frontier. The growth stocks - with or without NewConnect in the sample appear to be the crucial source of the reverse low-price anomaly on the Polish market.

\section{Catering Hypothesis}

Although we observe no significant low-price effect in Poland, and have identified a reverse phenomenon: the differences in performance between cheap and expensive stocks vary significantly in time. As a result, corporate managers may still have time-varying incentives to cater to investors with the nominal share price.
Table 5 reports the number of companies that split their shares as a percentage of all the companies within our sample. The splits were particularly popular in the years 2006-2008, when about 5-7\% of companies split their shares annually. Later the split frequency declined slightly to about $1-2 \%$ per year. Interestingly, the "split boom" in the years 2006-2008 followed the period of superior performance of cheap stocks relative to expensive companies. In Table 6 , we formally relate past returns to next-year's split frequency. We find strong, positive and significant correlation between the split frequency and the past cheap stock premium. Although not all correlation coefficients in Table 6 are significantly different from 0 , a positive correlation can be observed for all cheap stock premiums in the previous five years (it is, however, the strongest for the three year period). Furthermore, it is robust to changes in the detailed technique of zero-investment portfolio formation (equally- or capitalization-weighted, NewConnect included or excluded). Moreover, the positive correlation has been detected using both rank- and momentproduct-based methods. In other words, our results strongly support the catering hypothesis of Baker et al. (2009).

Share of stocks in the sample that split their shares

Table 5

\begin{tabular}{|c|c|c|c|c|c|c|c|c|c|c|c|c|c|c|}
\hline Year & 2001 & 2002 & 2003 & 2004 & 2005 & 2006 & 2007 & 2008 & 2009 & 2010 & 2011 & 2012 & 2013 & 2014 \\
\hline Splits & 1,54 & 0,00 & 0,00 & 0,68 & 3,94 & 6,64 & 7,01 & 5,07 & 1,28 & 2,48 & 1,87 & 1,38 & 0,62 & 1,77 \\
\hline
\end{tabular}

Notes. The table presents the share of a number of companies within the sample that split their shares in a given year. The values are expressed as percentages.

Table 6

Correlation between frequency of splits and the cheap stock premium

\begin{tabular}{|c|c|c|c|c|c|c|c|c|}
\hline & EW with NC & CW with $\mathrm{NC}$ & $\begin{array}{c}\text { EW without } \\
\text { NC }\end{array}$ & $\begin{array}{c}\text { CW without } \\
\text { NC }\end{array}$ & EW with NC & CW with $\mathrm{NC}$ & $\begin{array}{c}\text { EW without } \\
\text { NC }\end{array}$ & $\begin{array}{c}\mathrm{CW} \text { without } \\
\mathrm{NC}\end{array}$ \\
\hline & \multicolumn{4}{|c|}{ Spearman's rank correlation } & \multicolumn{4}{|c|}{ Pearson's product-moment correlation } \\
\hline \multirow[t]{2}{*}{ 1-year past return } & $0.55 *$ & $0.56 * *$ & 0.44 & 0.20 & 0.44 & 0.46 & 0.41 & 0.11 \\
\hline & $(1.91)$ & $(1.96)$ & $(1.46)$ & $(0.61)$ & $(1.47)$ & $(1.54)$ & $(1.32)$ & $(0.33)$ \\
\hline \multirow[t]{2}{*}{ 2-year past return } & $0.77 * *$ & $0.57 *$ & $0.77 * *$ & 0.25 & $0.71 * *$ & 0.45 & $0.69 * *$ & 0.12 \\
\hline & $(2.97)$ & $(1.90)$ & $(2.97)$ & $(0.75)$ & $(2.58)$ & $(1.41)$ & $(2.45)$ & $(0.34)$ \\
\hline \multirow[t]{2}{*}{ 3-year past return } & $0.81 * *$ & $0.63 * *$ & $\mathbf{0 . 7 8} * *$ & 0.43 & $0.84 * *$ & 0.48 & $0.86 * *$ & 0.33 \\
\hline & (3.09) & $(2.02)$ & $(2.88)$ & $(1.25)$ & (3.34) & (1.44) & $(3.58)$ & $(0.94)$ \\
\hline \multirow[t]{2}{*}{ 4-year past return } & $0.79 * *$ & 0.37 & $0.87 * *$ & $0.72 * *$ & $0.85 * *$ & 0.44 & $0.85 * *$ & 0.55 \\
\hline & $(2.78)$ & $(1.00)$ & (3.39) & (2.34) & (3.19) & $(1.20)$ & $(3.25)$ & $(1.58)$ \\
\hline \multirow[t]{2}{*}{ 5-year past return } & 0.60 & 0.20 & 0.55 & $0.82 * *$ & 0.59 & 0.36 & 0.58 & $0.71 * *$ \\
\hline & $(1.65)$ & $(0.48)$ & $(1.47)$ & $(2.73)$ & $(1.60)$ & $(0.89)$ & $(1.58)$ & $(2.13)$ \\
\hline
\end{tabular}

Notes. The table presents Spearman's rank correlations (Spearman, 1904) and Pearson's product-moment correlations (Pearson, 1920). The numbers in brackets denote $t$-statistics calculated using Fisher transformation (Fieler et al., 1957; Choi, 1977) and the significance at $5 \%$ level is in bold type. * and ** indicate values significantly different from 0 at $10 \%$ and $5 \%$ level, respectively. EW and CW refer to the equally- and capitalization-weighted portfolios, respectively, while NC refers to the NewConnect companies. 


\section{Concluding Remarks}

This study examines the low-price anomaly on the Polish market. Contrary to the numerous international studies, we have identified a reverse low-price effect, which leads to the observation that high-priced stocks significantly outperform low-priced stocks. The effect is particularly strong among growth companies and weakens slightly when NewConnect companies are excluded from the sample. Thus, we hypothesize that the anomalous Polish low-price effect may be related to the concept of lottery stocks. Moreover, we document that the relative performance of cheap stocks is correlated with the frequency of splits conducted by corporate managers.

These findings may have significant implications for investment practice and portfolio performance measurement. First, they may provide benefits to international investors who pursue factor strategies with a regional focus. Second, the low-price factor may be factored into the asset pricing model. Such a regionalized version of the model could be employed in evaluation of portfolio performance for both business (e.g. assessing the performance of fund manager) and academic (e.g. event studies) purposes.

Nevertheless, we should stress here that the results come with two important limitations: firstly, the research period includes the years of the global financial crisis, which may influence the findings; secondly, our study takes no account of transaction costs and liquidity constraints, which are largely investor-specific.

Further research should be pursued in a number of directions. First, market integration in terms of local and international low-price factors should be examined. Second, the interrelation between the low-price factor and other asset pricing effects, for example related to skewness (Harvey and Siddique, 2000) and volatility (Baker and Haugen, 2012; Frazzini and Pedersen, 2014), should be examined. The geographical focus should be extended to other emerging and developed markets. Finally, crosscountry comparisons would allow a deeper understating of the relationship between the low-price anomaly and the concept of lottery-like companies.

\section{Acknowledgments}

We thank Professor Adam Szyszka from the Warsaw School of Economics who provided insight that laid foundation for this research. This paper is a part of project no. DEC-2013/09/B/HS4/01335 financed by the National Science Centre of Poland.

\section{References}

Albuquerque, R. (2012). Skewness in Stock Returns: Reconciling the Evidence on Firm Versus Aggregate Returns. Review of Financial Studies, Society for Financial Studies, 25(5), 1630-1673. http://dx.doi.org/10.1093/rfs/hhr144

Alison, S. L., \& Heins, A. J. (1966). Some Factors Affecting Stock Price Variability. Journal of Business, 39(1), 19-23. http://dx.doi.org/10.1086/294827

Asygier, R. (2013). NewConnect in Comparison with Multilateral Trading Facilities in Europe. Irregularities in the Functioning of the Polish MTF Market. Proceedings of 2013 International Conference Technology Innovation and Industrial Management, 29-31 May 2013, Phuket, Thailand, pp. 38-54.

Bachrach, B., \& Galai, D. (1979). The Risk-Return Relationship and Stock Prices. Journal of Financial and Quantitative Analysis, 14(2), 421-441. http://dx.doi.org/10.2307/2330512

Baker, M., Greenwood, R. \& Wurgler, J. (2009). Catering through Nominal Share Prices. Journal of Finance, 64(6), 2559-2590. http://dx.doi.org/10.1111/j.1540-6261.2009.01511.x

Baker, N. L., \& Haugen , R. A. (2012). Low Risk Stocks Outperform within All Observable Markets of the World. Working paper available at SSRN: http://ssrn.com/abstract=2055431 or http://dx.doi.org/10.2139/ssrn.2055431. http://dx.doi.org/10.2139/ssrn.2055431

Bar-Yosef, S., \& Brown, L. D. (1979). Share Price Levels and Beta. Financial Management, 8(1), 60-63. http://dx.doi.org/10.2307/3665411

Blume, M. E., \& Husic, F (1973). Price, Beta and Exchange Listing. Journal of Finance, 28(2), $283-299$. http://dx.doi.org/10.1111/j.1540-6261.1973.tb01772.x

Branch, B., \& Chang, K. (1990). Low Price Stocks and the January Effect. Quarterly Journal of Business and Economics, 29(3), 90-118.

Choi, S. C. (1977). Tests of Equality of Dependent Correlation Coefficients. Biometrika, 64 (3), $645-647$. http://dx.doi.org/10.1093/biomet/64.3.645

Christie, A. A. (1982). The Stochastic Behaviour of Common Stock Variances - Value, Leverage and Interest Rate Effects. Journal of Financial Economics, 10(4), 407-432. http://dx.doi.org/10.1016/0304-405X(82)90018-6

Clenderin, J. C. (1951). Quality Versus Price as Factors Influencing Common Stock Price Fluctuations. Journal of Finance, 6(4), 398-405. http://dx.doi.org/10.1111/j.1540-6261.1951.tb04481.x

Clotfelter, Charles, T., \& Cook, Philip, J., (1990). On the Economics of State Lotteries. Journal of Economic Perspectives, 4(4), 105-119. http://dx.doi.org/10.1257/jep.4.4.105

Cochrane, J. H. (2001). Asset Pricing. Princeton University Press, Princeton. 
Czapkiewicz, A., \& Wojtowicz, T. (2014). The Four-Factor Asset Pricing Model on the Polish Stock Market. Economic Research - Ekonomska Istrazivanja, 27(1), 771-783. http://dx.doi.org/10.1080/1331677X.2014.975518

de Moor, L., \& Sercu, P. (2013). The Smallest Stocks Are Not Just Smaller: Global Evidence. European Journal of Finance, 21(2), 51-70.

Dubofsky, D. A., \& French, D. W. (1988). Share Price Level and Risk: Implications for Financial Management. Managerial Finance, 14(1), 6-9. http://dx.doi.org/10.1108/eb013591

European Commission (2012). Discrimination in th EU in 2012, Special Eurobarometer 393, available online: http://ec.europa.eu/public_opinion/archives/ebs/ebs_393_en.pdf

Eraker, B., \& Ready, M. (2015). Do investors overpay for stocks with lottery-like payoffs? An examination of the returns of OTC stock. Journal of Financial Economics, 115(3), 486-504. http://dx.doi.org/10.1016/j.jfineco.2014.11.002

Fama, E. F., \& French, K. R. (1993). Common risk factors in the returns on stocks and bonds. Journal of Financial Economics, 33, 3-56. http://dx.doi.org/10.1016/0304-405X(93)90023-5

Fama, E. F., \& French, K. R. (1995). Size and book-to-market factors in earnings and returns. The Journal of Finance, 50, 131155. http://dx.doi.org/10.1111/j.1540-6261.1995.tb05169.x

Fama, E. F., \& French, K. R. (2012). Size, Value, and Momentum in International Stock Returns. Journal of Financial Economics, 105(3), 457-472. http://dx.doi.org/10.1016/j.jfineco.2012.05.011

Fieller, E. C., Hartley, H. O., \& Pearson, E. S. (1957). Tests for rank correlation coefficients. I. Biometrika, 44, $470-481$. http://dx.doi.org/10.1093/biomet/44.3-4.470

Frazzini, A., \& Pedersen, L. H. (2014). Betting against Beta. Journal of Finacial Economics, 111, 1-25. http://dx.doi.org/10.1016/j.jfineco.2013.10.005

Fritzmeier, L. H. (1936). Relative Price Fluctuations of Industrial Stocks in Different Price Groups. Journal of Business, 9(2), 133-154. http://dx.doi.org/10.1086/232428

Gibbons, M. R., Ross, S. A., \& Shanken, J. (1989). A Test of the Efficiency of a Given Portfolio. Econometrica, 57, 11211152. http://dx.doi.org/10.2307/1913625

Goodman, D. A., \& Peavy III, J. W. (1986). The Low Price Effect: Relationship with other Stock Market Anomalies. Review of Business and Enonomics Research, 22(1), 18-37.

Grichting, W. L., (1986). The impact of religion on gambling in Australia. Australian Journal of Psychology, 38(1), 4558. http://dx.doi.org/10.1080/00049538608256416

Harvey, C.R. \& Siddique, A. (2000). Conditional Skewness in Asset Pricing Tests. Jounrnal of Finance, 55(3), $1263-1296$. http://dx.doi.org/10.1111/0022-1082.00247

Harvey, C.R., Liu, Y. \& Zhu, H. (2015), ... and the Cross-Section of Expected Returns (February 3, 2015). Available at SSRN: http://ssrn.com/abstract=2249314 or http://dx.doi.org/10.2139/ssrn.2249314. http://dx.doi.org/10.2139/ssrn.2249314

Hwang, S., \& Lu, C. (2008). Is Share Price Relevant? Working paper availabe at SSRN: http://papers.ssrn.com/sol3/papers.cfm? abstract_id=1341790.

Jacobs, H. (2015). What Explains the Dynamics of 100 Anomalies? Journal of Banking \& Finance, 57, 65-85. http://dx.doi.org/10.1016/j.jbankfin.2015.03.006

Kahneman, D., \& Tversky, A. (1979). Prospect Theory: An Analysis of Decision under Risk. Econometrica, 47(2), $263-291$. http://dx.doi.org/10.2307/1914185

Kumar, A. (2009). Who Gambles in the Stock Market? Journal of Finance, 64(4), 1889-1933. http://dx.doi.org/10.1111/ j.1540-6261.2009.01483.x

Kumar, A., Page, J. K., \& Spalt, O. G. (2011), Religious beliefs, gambling attitudes, and financial market outcomes. Journal of Financial Economics, 102(3), 671-708. http://dx.doi.org/10.1016/j.jfineco.2011.07.001

Lakonishok, J., Schleifer, A., \&Vishny, R. W. (1994). Contrarian Investment, Extrapolation, and Risk. The Journal of Finance, 49(5), 1541-1578. http://dx.doi.org/10.1111/j.1540-6261.1994.tb04772.x

Patton, A. J., \& Timmermann, A. (2010). Monotonicity in Asset Returns, New Tests with Applications to the Term Structure, the APM and Portfolio Sorts. Journal of Financial Economics, 98, 605-625. http://dx.doi.org/10.1016/j.jfineco.2010.06.006

Pearson, K. (1920). Notes on the History of Correlation. Biometrika, 13, 25-45. http://dx.doi.org/10.1093/biomet/13.1.25

Shefrin, H., \& Statman, M. (2000). Behavioral Portfolio Theory. Journal of Financial and Quantitative Analysis, 35(2), 127-151. http://dx.doi.org/10.2307/2676187

Spearman, C. E (1904). The Proof and Measurement of Association Between Two Things. American Journal of Psychology, 15, 72-101. http://dx.doi.org/10.2307/1412159

Strong, R. A. (1983). Do Share Price and Stock Splits Matter? Journal of Portfolio Management, 10(1), 58-64. http://dx.doi.org/10.3905/jpm.1983.408940

Willenbrock, S. (2011). Diversification Return, Portfolio Rebalancing, and the Commodity Return Puzzle. Financial Analyst Journal, 67(4), 42-49. http://dx.doi.org/10.2469/faj.v67.n4.1 
Adam Zaremba, Szymon Okon, Andrzej Nowak, Przemysław Konieczka. The Low Price Anomaly: the Intriguing Case...

Zaremba, A., \& Konieczka, P. (2014). Paper Profits from Value, Size and Momentum: Evidence from the Polish Market. Financial Internet Quarterly ,e-Finanse”, 11(3), 58-69. http://dx.doi.org/10.2139/ssrn.2375234

Zaremba, A., \& Zmudzinski, R. (2014). The Low Price Effect on the Polish Market. Financial Internet Quarterly „e-Finanse”, 10(1), 69-85. http://dx.doi.org/10.2139/ssrn.2374694

Zaremba, A. (2014). Cross-Sectional Asset Pricing Models for the Polish Market. Working paper available at SSRN: http://ssrn.com/abstract=2396884 or http://dx.doi.org/10.2139/ssrn.23968

The article has been reviewed.

Received in October 2015; accepted in April, 2016. 